Recepción: 18 / 03 / 2018

Aceptación: 27 / 05 / 2018

Publicación: 05 / 06 / 2018

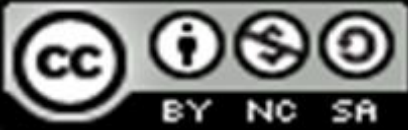

Ciencias de la salud Artículo de Investigación

\title{
Falta de mantenedores de espacios en niños de 5-7 años
}

\section{Lack of space maintainers in children 5-7 years}

\section{Falta de mantenedores de espaço em crianças de 5 a 7 anos}

\author{
Juan Oliveira-del Río I \\ juanoliveiradelrio@hotmail.com \\ Lourdes A. Rivadeneira-Proaño II \\ lourdesrivadeneira@ hotmail.com \\ Walther J. Loor-Marcillo III \\ walterloor@hotmail.com
}

Correspondencia: juanoliveiradelrio@hotmail.com

\footnotetext{
${ }^{\text {I }}$ Doctor en Ciencias Odontológicas, Docente en la Universidad Laica "Eloy Alfaro" de Manabí, Manta, Ecuador.

II Odontóloga, Diploma Superior en Odontología Integral, Residente del post-grado de Odontopediatría de la Universidad de Carabobo, Venezuela.

III Odontólogo, Docente en la Universidad Estatal del Sur de Manabí, Jipijapa, Ecuador.
} 


\title{
Resumen
}

Se realizó un estudio descriptivo transversal, con la finalidad de identificar la falta de mantenedores de espacio en el grupo de edades de 5 - 7 años. La población en estudio estuvo conformada por 113 niños. La información obtenida se procesó mediante el paquete estadístico SPSS-11.5.1 y se utilizó el porcentaje como medida de resumen. En la serie, predomino el sexo masculino $60.1 \%$ y la edad de 7 años $55.7 \%$. Según el criterio de necesidad de mantenedores de espacios, el $31.8 \%$ de los examinados necesitaban y el $68.1 \%$ no necesitaban, por edad prevaleció la edad de 7 años.

Palabras clave: mantenedores de espacio; escolares.

\begin{abstract}
A transversal descriptive study was carried out, with the purpose of identifying the lack of space maintainers in the age group of $5-7$ years. The study population consisted of 113 children. The information obtained was processed using the statistical package SPSS-11.5.1 and the percentage was used as a summary measure. In the series, the male sex predominated $60.1 \%$ and the age of 7 years $55.7 \%$. According to the criterion of need for space maintainers, $31.8 \%$ of the examinees needed and $68.1 \%$ did not need, by age the age of 7 years prevailed.
\end{abstract}

Keywords: space maintainers; school.

\section{Resumo}

Foi realizado um estudo descritivo transversal, com o objetivo de identificar a falta de mantenedores de espaço na faixa etária de 5 a 7 anos. A população do estudo consistiu de 113 crianças. As informações obtidas foram processadas utilizando o pacote estatístico SPSS-11.5.1 e a porcentagem foi utilizada como uma medida resumida. Na série, o sexo masculino predominou em $60,1 \%$ e a idade de 7 anos em 55,7\%. De acordo com o critério de necessidade de mantenedores de espaço, $31,8 \%$ dos examinandos precisavam e $68,1 \%$ não necessitavam, por idade, a idade de 7 anos prevaleceu.

Palavras chave: mantenedores de espaço; escola. 


\section{Introducción}

Durante el crecimiento y desarrollo cráneo-facial ocurre un cambio continuo en la dentición del niño, los dientes temporales hacen erupción y con ello estimulan la formación de hueso alveolar. Debido a la naturaleza transicional de ésta dentición, se hace necesaria una vigilancia muy estrecha para intervenir en cuanto se haga aparente cualquier cambio perjudicial; con el objetivo de guiar los dientes hacia una correcta posición, y por tanto, hacia una oclusión normal. ${ }^{1}$

La oclusión se establece como resultado de la interacción de factores genéticos y ambientales, los cuales varían de intensidad de acuerdo a las características individuales de cada sujeto. Entre las variables que tienen mayor influencia en el desarrollo de la oclusión dental, destaca la vulnerabilidad de la dentición primaria al ataque de la caries dental, pues ésta puede propiciar tanto la pérdida de espacio, cuando las lesiones son amplias y se encuentran ubicadas interproximalmente, como la pérdida prematura de uno o más dientes afectados. ${ }^{2}$

Se considera pérdida prematura de dientes primarios cuando éstos se exfolian o son extraídos antes del momento fisiológico de recambio. Sus consecuencias incluyen cambios en el plano sagital: pérdida de perímetro de arco y longitud de arco por migración mesial de los molares permanentes, y por distoinclinación o retrusión de los dientes anteriores, pérdida del espacio disponible para la correcta alineación de los dientes permanentes, lo cual producirá apiñamiento, erupción ectópica o impactación dentaria. En el plano vertical, producen profundización de la mordida y en el plano transversal, mordida cruzadas. ${ }^{3}$

En muchos niños entre 4 y 9 años la exfoliación prematura de la dentición temporal por caries es común, otras causas influyen trauma, erupción ectópica, desordenes congénitos y diferencias de longitud que causan reabsorciones de las piezas temporales. ${ }^{4}$

Los mantenedores de espacio son aparatos ortodóncicos que pretenden impedir el cierre de espacio, seguido de la pérdida prematura de un diente primario. Se clasifican en fijos y removibles de acuerdo a su retención. Para su colocación deben ser tomados en cuenta ciertos factores como son: la edad a la que ocurrió la pérdida, tipo de diente perdido, presencia del diente sucesor, análisis del espacio disponible y tiempo transcurrido desde la pérdida. Su uso es indicado por la mayoría de los autores, aunque para Ngan 199611, Ghafari 1986 y Woodward 1989 citado por Brothwell 19976 sugieren que en algunos casos puede ser innecesario su uso. ${ }^{2}$ 
El objetivo de este trabajo fue identificar la falta de mantenedores de espacio en el grupo de edades de $5-7$ años y evaluar su relación con la edad.

\section{Metodología.}

Se realizó un estudio descriptivo transversal con la finalidad de identificar la falta de mantenedores de espacio en el grupo de edades de $5-7$ años.

La población en estudio estuvo conformada por 113 niños.

Como método de obtención de datos se utilizó la entrevista y la observación directa (examen clínico).

El examen clínico se ejecutó con el paciente recostado en el sillón dental utilizando luz artificial y mediante la inspección visual por el mismo examinador.

Para determinar que niños necesitaban mantenedores de espacio se utilizó el siguiente criterio: si la pieza se había perdido hace menos de seis meses o si se encontraba cariada e indicada para extracción.

La higiene bucal se considera como:

- Buena: Cuando el índice de higiene bucal de Love se encuentra por debajo del $20 \%$

- Deficiente: Cuando el índice de higiene bucal de Love se encuentra por encima del $20 \%$.

Para determinar la higiene bucal utilizamos el índice de Love cuya fórmula es la siguiente:

Índice de Love $=($ Superficies coloreadas $/$ superficies examinadas $) * 100$.

El índice bucal de Love es cuantitativo y objetivo. Se utiliza si hay 6 o más dientes presentes en la cavidad bucal.

Se valorarán las superficies mesial, distal, vestibular y lingual de todos los dientes presentes en la cavidad bucal.

Se observarán las superficies coloreadas y anotaremos en un formulario con un punto rojo. Los dientes ausentes serán señalados con una línea horizontal. ${ }^{5}$ 
La información obtenida se procesó mediante el paquete estadístico SPSS-11.5.1 y se utilizó el porcentaje como medida de resumen

\section{Resultados}

De los 113 niños examinados tabla 1 predomino el sexo masculino $60.1 \%$ y la edad de 7 años $55.7 \%$.

Tabla 1. Distribución de pacientes por edades.

\begin{tabular}{|c|c|c|c|c|c|c|}
\hline \multirow{2}{*}{ Edad } & \multicolumn{2}{|c|}{ Masculino } & \multicolumn{2}{c|}{ Femenino } & \multicolumn{2}{c|}{ Total } \\
\cline { 2 - 7 } & No & $\mathbf{\%}$ & No & \% & No & $\%$ \\
\hline 5 & 13 & 19.1 & 12 & 26.6 & 25 & 22.1 \\
\hline 6 & 10 & 14.7 & 15 & 33.3 & 25 & 22.1 \\
\hline 7 & 45 & 66.1 & 18 & 40 & 63 & 55.7 \\
\hline Total & $\mathbf{6 8}$ & $\mathbf{6 0 . 1}$ & $\mathbf{4 5}$ & $\mathbf{3 9 . 8}$ & $\mathbf{1 1 3}$ & $\mathbf{1 0 0}$ \\
\hline
\end{tabular}

Según el criterio de necesidad de mantenedores de espacios, el $31.8 \%$ de los examinados necesitaban y el $68.1 \%$ no necesitaban, por edad prevaleció la edad de 7 años (tabla 2). Con respecto al sexo, 20 eran del sexo masculino y 16 femenino.

Tabla 2. Distribución de niños con necesidad de mantenedores de espacios.

\begin{tabular}{|c|c|c|}
\hline \multirow{2}{*}{ Edad } & \multicolumn{2}{|c|}{ Necesidad de mantenedores de espacios } \\
\cline { 2 - 3 } & No & \% \\
\hline 5 & 2 & 5.5 \\
\hline 6 & 8 & 22.2 \\
\hline 7 & 26 & 72.2 \\
\hline Total & $\mathbf{3 6}$ & $\mathbf{3 1 . 8}$ \\
\hline
\end{tabular}

Como se observa en la tabla 3, la higiene bucal fue evaluada de mala en el $76.1 \%$ de niños examinados, solamente el $23.8 \%$ fue buena. 
Tabla 3 Higiene bucal en niños con necesidad de mantenedores de espacios.

\begin{tabular}{|c|c|c|}
\hline Higiene bucal & No & $\boldsymbol{\%}$ \\
\hline Buena & 27 & 23.8 \\
\hline Mala & 86 & 76.1 \\
\hline Total & $\mathbf{1 1 3}$ & $\mathbf{1 0 0}$ \\
\hline
\end{tabular}

El $80 \%$ de la pérdida dentaria fue por caries dentales, el resto se distribuyó en trauma, erupción ectópica.

\section{Discusión}

La pérdida prematura de los dientes primarios, es el problema más frecuente encontrado en países donde la caries dental sigue siendo un problema de salud pública, ya que ella puede, conducir a la pérdida prematura total o parcial de los dientes primarios, trae como consecuencia que se acorte la longitud del arco, así que la acción primera debe de ser dirigida hacia el cuidado y el mantenimiento de la integridad de los dientes. Para evitar movimientos indeseables y anomalías dentomaxilares, generalmente es necesario utilizar mantenedor de espacio. ${ }^{6-7}$

Una parte importante dentro de la prevención de las maloclusiones, lo constituye el manejo adecuado de los espacios creados por la pérdida prematura de los dientes temporales pues además de la resultante migración de los dientes adyacentes y antagonistas podrían instaurarse hábitos deletéreos, lo que impediría que se establezca una correcta oclusión. Al perderse un diente se verán afectadas funciones tales como la masticación y la fonación. La estética por su parte estaría comprometida si la pérdida ocurriese en el sector anterior. ${ }^{8}$

La constante actividad que desarrollan los niños en edad escolar, los conllevan a que se produzcan muchas lesiones provocadas por traumatismo. Los dientes temporarios que con más frecuencia se pierden son los anteriores superiores, y entre ellos los centrales. La pérdida de estos dientes no siempre indica que se cerrará el espacio, pues entre ellos existen diastemas que con el desarrollo de los segmentos posteriores, lejos de desaparecer se mantienen y hasta pueden aumentar, no obstante el descuido o despreocupación ante el problema, puede acarrear complicaciones futuras en el desarrollo de la dentición permanente. ${ }^{9}$ 
En la investigación se demostró el alto por ciento de niños con pérdida prematura de dentición temporal, coincidiendo con los resultados de Alvear $\mathrm{P} .{ }^{4} \mathrm{El}$ factor de riesgo que predominó fue las caries dentales y la mala higiene bucal.

Así mismo, la relación estudiada entre la edad y necesidad de mantenedores de espacio no es estadísticamente significativa, dichos resultados también coinciden con Alvear $\mathrm{P}^{4}$. Esto sugiere que, una pieza por estar no deba tener más daños por permanecer más tiempo en la cavidad bucal.

Se concluye, los mantenedores de espacio, son los aditamentos ideales para la prevención de maloclusiones, esta técnica preventiva de fácil diseño y construcción puede ser desarrollada no solo por el ortodoncista sino por otras especialidades como la Rehabilitación Protésica, y la Odontología General Integral.

\section{Referencias Bibliográficas}

1. García Peláez Soledad Yanedy, Martín Zaldivar Ledia, Lage Ugarte Maité, Altunaga Carbonel Ana. El mantenedor de espacio en la prevención de maloclusiones. AMC. 2014 Abr [citado 2017 Mayo 24]; 18(2): 193-199. Disponible en: http://scielo.sld.cu/scielo.php?script=sci_arttext\&pid=S1025-02552014000200005\&lng=es.

2. Rivero García N, Medina A, Gabriela Martínez R, Prieto M. Utilización de mantenedores de espacio en pacientes con pérdidas prematuras de dientes primarios. 2012. Rev Odontopeditria Latinoamericana. 2 (2),

3. García Y, Da Silva L, Medina A, Crespo O. Efecto de la pérdida prematura de molares primarios sobre la relación horizontal incisiva. Rev. Odontopediatr Latinoam. 2011; 1(1): 49-57.

4. Alvear P, Fierro C, Pérez A. Necesidad de mantenedores de espacios. Oral Res 2012. 1(1); 1921

5. González Naya G, Montero del Castillo M. Estomatologia General Integral. Capitulo I. Sosa Rosales M. Epidemiologia de las Enfermedades Bucales más frecuentes. Editorial Ciencias Médicas. Cuba. 2013 
6. Gross EL, Leys EJ, Gasparovich SR, Firestone ND, Schwahtzbaum JA, Janies DA, et al. Bacterial $16 \mathrm{~S}$ sequence analysis of severe caries in Young permanent teeth. J Clin Microbiol. 2010;48(11):4121-8.

7. González Naya G, Garmendia Hernández G, Granados Martínez AM, Beauballet Fernández B. Guías Prácticas Clínicas Ante Traumatismos Dentarios y Faciales. En: Sosa Rosales M de la C, Salas Adam MR, editores. Guías prácticas de Estomatología. La Habana: Editorial Ciencias Médicas; 2003. p. 128-30.

8. García Peláez Soledad Yanedy, Martín Zaldivar Ledia, Lage Ugarte Maité, Altunaga Carbonel Ana. El mantenedor de espacio en la prevención de maloclusiones. AMC. 2014 Abr [citado 2017 Mayo 26]; 18(2): 193-199. Disponible en: http://scielo.sld.cu/scielo.php?script=sci_arttext\&pid=S1025-02552014000200005\&lng=es.

9. Sosa Rosales M de la C, Salas Adam MR. Promoción de Salud y Prevención de Enfermedades En: Sosa Rosales M de la C, Salas Adam MR, editores. Guías prácticas de Estomatología. La Habana: Editorial Ciencias Médicas; 2003. p. 508 